are abolished. Success rates of $100 \%$ have been claimed. ${ }^{9}$

Recently, Brandt has developed the technique of vestibular habituation training, specifically for use in benign paroxysmal positional vertigo - it encourages patients to repeatedly adopt the position that provokes their attacks until they diminish or disappear completely. Vestibular habituation training is easily learned by the patient and repeated at home. Response rates over $90 \%$ have been claimed, ${ }^{5}$ but whether the technique disperses otoliths, encourages central compensation for the abnormal vestibular input, or increases patients' confidence in dealing with potentially frightening symptoms is unknown.

In the few patients who develop persistent and disabling symptoms surgery may be considered, but positional nystagmus of central origin should be excluded first. The operation of singular neurectomy, which selectively denervates the posterior semicircular canal, is a logical and effective procedure, producing up to $100 \%$ success rates. The operation carries a substantial risk of sensorineural deafness and is technically demanding. ${ }^{10}$ Intracranial vestibular nerve section has been performed and, in those patients with no useful hearing in the affected ear, labyrinthectomy is an option.

Recently transmastoid procedures that occlude the posterior canal with bone dust or partition the labyrinth using a laser have been described. ${ }^{112}$ These are simpler to perform and reportedly carry less risk of permanent sensorineural deafness than singular neurectomy.
Clinical and pathological evidence suggests that the symptoms of benign paroxysmal positional vertigo arise from the posterior semicircular canal. Further pathological studies are required, however, before the theory of cupulolithiasis can be confidently supported. The newly described technique of vestibular habituation training is likely to benefit most patients with the condition. The few who have persistent and disabling symptoms should be considered for occlusion of their posterior semicircular canal.

STUART W DENHOLM Senior registrar in ENT

Singleton Hospital,

Swansea, SA2 8AQ 1 Bárány R. Diagnose von Krankheitserscheinungen im Bereiche des Otolithenapparates. Acta
Otorlaryngol 1921;2:434-7.
2 Dix MR, Hallpike CS. The pathology, symptomatology and diagnosis of certain disorders of the
vestibular system. Proc Roy Soc Med 1952;45:341-54.
3 Schuknecht HF. Cupulolithiasis. Arch Otolaryngol 1969;90:765-78.
4 Barber HO. Positional nystagmus, especially after head injury. Laryngoscope 1964:74:891-944.
5 Brandt T. Man in motion. Brain 1991;114:2159-74.
6 Harbert F. Benign paroxysmal positional nystagmus. Arch Ophthalmol 1970;84:298-302.
7 Baloh RW, Honrubia V, Jacobson K. Benign postural vertigo, clinical and oculographic features in
240 cases. Neurology 1987;37:371-8.
8 Cooksey FS. Rehabilitation in vestibular injuries. Proc Roy Soc Med 1945;39:273-8.
9 Epley JM. The canalith repositioning procedure: for treatment of benign paroxysmal positional
vertigo. Otolaryngol Head Neck Surg 1992;107:399-404.
10 Gacek R. Transection of the posterior ampullary nerve for relief of BPPV. Ann Otol Rhinol Laryngol
1974;83:596-605.
11 Parnes LS, McClure JA. Posterior semi circular canal occlusion in the normal hearing ear.
Otolaryngol Head Neck Surg 1991;104:52-7.
12 Anthony DF. Partitioning of the labyrinth. Application benign paroxysmal positional vertigo.
Am f Otol 1991;12:388-93.

\title{
Sunbeds and the pursuit of the year round tan
}

\section{Should be discouraged}

The perception of a suntan as an essential component of a socially desirable appearance is a relatively recent phenomenon. Victorian ladies preferred to remain pale and interesting, lest they be confused with the lower classes who toiled in the fields. But over the past 20 years developing and maintaining a year round suntan has become a social necessity for some people. Manufacturers of sunbeds and those promoting their use obviously have an economic interest in persuading people that a glowing tan is a visible sign of good health, and they would no doubt claim that they are merely satisfying public demand.

Some of the current promotional literature is clearly designed to reassure prospective purchasers that acquiring a tan on a sunbed is entirely safe. One large European manufacturer of sunbeds that emit ultraviolet $\mathrm{A}$ radiation states that "incorrect and uninformed reports on the negative effects of the sun and sunbeds fuel hysteria and even panic." The same manufacturer states testimonial support to suggest that using sunbeds can inhibit the development of both melanoma skin cancer and internal cancer, stimulate the immune system, and "regenerate calcium for building our bones."

Undoubtedly, this and similar sale pitches have impressed the public: an estimated 80000 machines for home use were sold in 1988 compared with 5000 in $1982 .{ }^{1}$ This is in addition to the widely available tanning facilities in beauty salons and municipal and private sports centres. Regular users tend to be young (16-30 years), female, ${ }^{2}$ and given the cost, relatively affluent. When suntanning facilities are located at sites where sport and fitness are promoted (for example, swimming pools and gymnasiums) there is probably an implicit assumption of "health by association." Little evidence exists that recent publicity campaigns alerting people to the dangers of excessive exposure to ultraviolet light have so far had much effect.
Almost all modern commercially available sunbeds emit predominantly ultraviolet A radiation (315-380 nm), although small amounts of ultraviolet $B$ radiation (280-315 nm) are also present. The degree of tanning produced by these machines varies and depends largely on the skin type of the user. ${ }^{3}$ From the purely cosmetic aspect, patients who burn or tan poorly in natural sunlight will fare no better on a sunbed, although the risks of producing acute erythema (sunburn) may be somewhat reduced. Even subjects who develop some degree of tanning will find that this offers only very limited protection against subsequent burning when exposed to natural sunlight. ${ }^{3}$ This is clearly important to those who believe that a few sessions on a sunbed before a fortnight on a Mediterranean beach will prevent sunburn, especially as acute blistering sunburn is now considered to be a major risk factor for the subsequent development of malignant melanoma. ${ }^{4}$

Repeated exposure to ultraviolet A radiation often leads to increased skin wrinkling, irregular pigmentation, and altered skin texture (photoaging). These are not usually considered to be cosmetically desirable effects, and some people subsequently seek reversal of these changes (at even greater expense). Equally undesirable are the deeply pigmented freckles ("sunbed lentigines") that occur in some users, especially as dysplastic cellular changes may occur within these lesions. ${ }^{5}$ Regular users may also develop increased skin fragility and blistering (pseudoporphyria). ${ }^{6}$

Some people should be specifically warned against the use of sunbeds. These include patients with a known pre-existing photodermatosis such as lupus erythematosus and those taking drugs or using cosmetics with a photosensitising potential. Patients with multiple melanocytic naevi, especially those with the dysplastic naevus syndrome, should also avoid sunbeds (as well as undue exposure to natural sunlight). 
Far from improving the performance of the immune system, there is increasing evidence that ultraviolet A radiation has both local and systemic immunosuppressive effects. ${ }^{37}$ Such exposure may activate and accelerate the growth of human viruses, including HIV. ${ }^{8}$ This has important implications for patients who are HIV positive, especially if they believe that acquiring a tan will improve their general health. In a study of HIV positive male homosexuals, two thirds thought that a suntan would improve their health and the outcome of their HIV infection; use of sunbeds on a regular basis was also higher in this group than in controls. ${ }^{9}$

Of course, the primary concern is whether regular sunbed use can lead to the development of skin cancer, especially malignant melanoma. Mice exposed to ultraviolet A radiation in doses normally used in tanning salons develop skin tumours, and pretreatment with ultraviolet $\mathrm{A}$ radiation enhances tumour development when followed by exposure to simulated solar ultraviolet radiation. ${ }^{10}$ Extrapolation from animal studies suggests that the risk of non-melanoma skin cancer in humans is about doubled if sunbeds are used for no more than 20 sessions a year over a lifetime. ${ }^{11}$ Unfortunately there are still no long term studies in humans to confirm or refute this. But case-control studies suggest an increased risk of melanoma in sunbed users. ${ }^{1213}$

The British Photodermatology Group has drawn attention to the potential risks, ${ }^{14}$ and the International Non-Ionising Radiation Committee has reiterated them. ${ }^{15}$ Both groups have reviewed the scientific evidence and concluded that tanning with sunbeds that emit ultraviolet $A$ radiation should be discouraged. Despite this, the marketing and use of sunbeds remains entirely unregulated in Britain. Potential sunbed users need to be better informed of the damaging effects that regular exposure to ultraviolet A radiation may have on their skin.

DAVID SHUTTLEWORTH Consultant dermatologist

Essex County Hospital,

Colchester CO3 3NB

1 Marks R. Sun damaged skin. London: Dunitz, 1992

2 Diffey BL Use of UV-A sunbeds for cosmetic tanning. Br 7 Dermatol 1986;115:67-76.

3 Rivers JK, Norris PG, Murphy GM, Chu AC, Midgley G, Morris J, et al. UVA sunbeds: photoprotection, acute adverse effects and immunological changes. $B r f$ Dermatol 1989;120: 767-77.

4 Mackie R, Aitchison T. Severe sunburn and subsequent risk of primary cutaneous malignant melanoma in Scotland. Br f Cancer 1982;46:955-60.

Jones SK, Moseley H, Mackie RM. UVA-induced melanocytic lesions. Br f Dermatol 1987;217: 111-5.

6 Murphy GM, Wright J, Nicholls DS, McKee PH, Messenger AG, Hawk JL, et al. Sunbed-induced pseudoporphyria. $\mathrm{Br}$ f Dermatol 1989;120:555-62.

7 Hersey P, MacDonald M, Henderson C, Schibeci S, D'Alessandro G, Pryor M, et al. Suppression of natural killer cell activity in humans by radiation from solarium lamps depleted of UVB. of natural killer cell activity in

$8 \mathrm{Zmudzka} \mathrm{BZ}$, Beer JZ. Activation of human immunodeficiency virus by ultraviolet radiation Photochem Photobiol 1990;52:1153.

9 Flegg PJ. Potential risks of ultraviolet radiation in HIV infection. International foumal of STD and AIDS 1990;1:46-8.

10 Bech-Thomsen N, Wulf HC, Poulsen T, Christensen FG, Lundgren K. Photocarcinogenesis in hairless mice induced by ultraviolet $\mathrm{A}$ tanning devices with or without subsequent solarsimulated ultra-violet irradiation. Photodermatol Photoimmunol Photomed 1991;8:139-45.

11 Diffey BL. Analysis of the risk of skin cancer from sunlight and solaria in subjects living in northern Europe. Photodermatology 1987;4:118-26.

12 Swerdlow AJ, English JSC, Mackie RM, O'Doherty CJ, Hunter JA, Clark J, et al. Fluorescent lights, ultraviolet lamps, and risk of cutaneous melanoma. $B M \mathcal{F}$ 1988;297:647-50.

13 Walter SD, Marrett LD, From L, Hertzman C, Shannon HS, Roy P. The association of cutaneous malignant melanoma with the use of sunbeds and sunlamps. Am 7 Epidemiol 1990;131:232-43.

Diffey BL, Farr PM, Ferguson J, Gibbs NK, deGruijl FR, Hawk JL, et al. Tanning with ultraviolet A sunbeds $B M Y$ 1990;301:773-4.

15 Health issues of ultraviolet A sunbeds used for cosmetic purposes. Health Phys 1991;61:285-8.

\section{Making murder sound respectable}

\section{Time for the European Union to ban tobacco promotion}

"Political language," wrote George Orwell, "is designed to make lies sound truthful and murder respectable, and to give an appearance of solidity to pure wind." The central talent of politicians may be to sound convincing when insisting on the truthfulness of something that almost everybody knows to be untrue. Virginia Bottomley, secretary of state for health in England, tries hard to tell the British public that it would be a mistake to ban tobacco promotion, but she is mostly not believed. What's more, she opposes a ban on tobacco promotion while simultaneously reminding us that smoking is the single largest cause of preventable death and bemoaning the fact that smoking is not decreasing among young people. It may be these contortions that led recently to her being voted the most insincere politician in Britain-against some very tough opposition. ${ }^{2}$

The issue of banning tobacco advertising comes up yet again because next week the council of health ministers of the European Union, including Mrs Bottomley, will once again debate the draft directive to ban cigarette advertising. Most Europeans and most European health ministers want such a ban, and bans already operate in France, Italy, and Portugal. Mrs Bottomley is expected to oppose the ban (as she has done before)-together with ministers from Germany, the Netherlands, and Denmark - and so prevent it being passed. If she voted for the ban it would pass.

Doctors, who every day deal with the carnage that results from smoking, cannot understand why the government refuses to act. Nobody, and certainly not the government, disputes that tobacco does enormous damage, although people may not quite grasp the scale-that smoking kills about 115000 people a year in Britain and accounts for more than a quarter of deaths in middle age. ${ }^{3}$ There is also abundant evidence that cigarette advertising makes a considerable impact on children and young people, ${ }^{4}$ and the government's own data show that young people are the one group who are not reducing their rates of smoking. ${ }^{5}$ Reducing rates of smoking among teenagers was one of the targets of the Health of the Nation, ${ }^{6}$ and the government has conceded that the target for 1994 will not be met. ${ }^{7}$ This is particularly sad as $90 \%$ of smokers begin in their teenage years; within a few years three out of four are trying to stop but failing. ${ }^{4}$

Nor is there much dispute-except from the tobacco industry-that banning tobacco promotion would reduce smoking. ${ }^{8}$ The Department of Health's own report suggested, after a survey of evidence from countries that had introduced bans, that a ban would lead to a drop in rates of smoking of between $4 \%$ and $9 \% .{ }^{9}$ In Canada, where a ban was introduced in 1989 as part of a comprehensive antismoking package, cigarette consumption fell by $37 \%$ between 1981 and $1992-$ with the biggest falls occurring in 1989 and $1990 .{ }^{10}$ Most importantly-and in complete contrast to what happened in Britain-the greatest improvement was in smoking among adolescents, which halved from 1979 to $1991 .^{10}$

What Britain needs is a comprehensive anti-tobacco package. A ban on promotion is only one part of the package, and the government has done better at increasing the price of cigarettes. But a ban on promotion has immense symbolic as well as practical importance-and it would be particularly effective with adolescents. Young people are very sensitive to hypocrisy in their seniors, and many think that "Smoking 